\title{
A model of patient-centred care - turning good care into patient-centred care
}

\author{
S. Scambler ${ }^{* 1}$ and K. Asimakopoulou'
}

IN BRIEF

- Stresses the importance of patientcentred care in dentistry and what this really means.

- Proposes a hierarchy of patientcentredness that may aid the practical application of patient-centred care in clinical practice.

- Encourages open, unambiguous communication in dental consultations.

This paper builds on previous work reviewing patient-centred care in dentistry and acknowledges work that has questioned the measurement and effectiveness of patient-centredness in practice. In an attempt to move the debate from rhetoric to practice and enhance the practical utility of the concept, we present a practical hierarchy of patient-centredness that may aid the practical application of patient-centred care in clinical practice by making explicit a series of stages that a dental care professional needs to move through in order to provide care that is patient-centred. The model presented is illustrated through practical examples. The various stages inherent in it are described with the aim of making clear the perhaps automatic and taken for granted assumptions that are often made by dental care professionals and patients through the course of a consultation. Our aim is to encourage dental consultations to have more open, unambiguous communication, both about the risks and benefits of courses of action and about the choices available to patients.

\section{INTRODUCTION}

The Institute of Medicine has defined patientcentred care (PCC) as: 'Providing care that is respectful of and responsive to individual patient preferences, needs, and values, and ensuring that patient values guide all clinical decisions. ${ }^{1}$ Thus, PCC is a mode of healthcare delivery that puts the patient at the forefront of all decision-making and treatment. PCC is a popular concept that has been associated with tangible benefits in physical and psychological outcomes ${ }^{2,3}$ and is adopted by healthcare systems such as the UK's National Health Service (NHS).

In the recent UK National Institute for Health and Care Excellence (NICE) guidance $^{4}$ for example, a set of 14 principles were outlined, all of which aim to make the experience of adults using the NHS more patient-centred. These principles range from the most basic standard of the need to treat patients with dignity, kindness, compassion, courtesy, respect, understanding and honesty (principle one), to patients being actively involved in shared decision making, supported in making decisions about treatment that are important to them (principle

King's College London, Unit of Social and

Behavioural Sciences, Caldecot Road, Denmark Hill, London, SE5 9RW

* Correspondence to: Sasha Scambler

Email: sasha.scambler@kcl.ac.uk

\section{Refereed Paper}

Accepted 20 May 2014

DOI: 10.1038/sj.bdj.2014.755

${ }^{\circ}$ British Dental Journal 2014; 217: 225-228 six) and experiencing care that is tailored to their needs and personal preferences (principle nine).

Although both the academic literature and practical recommendations to clinicians through NICE endorse PCC, the extent to which these ideas have truly transferred into medicine or dentistry remains unknown. The UK General Dental Council (GDC) Standards for the dental team, ${ }^{5}$ for instance, set out the principles that the dental team should follow. The principles are fairly prescriptive and the Council's recommendation is that these principles should influence all areas of practice. Within this GDC document, standard two is about 'respecting patients' dignity and choices'. Here, it is explicitly stated that the dental team should 'recognise and promote patients' responsibility for making decisions about their bodies, their priorities and their care... ${ }^{5}$

The above statement, although making explicit the need for dental professionals to be patient-centred in a way that patients are encouraged to have some responsibility about decision-making in a dental consultation, does not clearly identify the details of this process. It further fails to differentiate between different contexts and professionals or give examples of how GDC members might implement this standard in day-today clinical practice. This has implications for a team seeking to provide PCC. Many of the papers published in the dental literature that explicitly talk about PCC use the term to refer to provision of care that is holistic and humanistic, ${ }^{6-12}$ while others talk about respecting patients' decisions, communicating effectively, being flexible in decisionmaking and making patients feel good about the treatment they are receiving. ${ }^{13-15}$ There are several papers ${ }^{16-22}$ that highlight the need for patients to be provided with information and to be made aware that they have a choice as to what treatment to undertake, moving towards a more practical understanding of PCC, but only three papers ${ }^{23-25}$ explicitly talk about informed choice and providing patients with the tools necessary to make such a choice. A recent review of PCC in the dental literature ${ }^{26}$ further demonstrates this lack of understanding of what PCC means in a dental context. The authors go further to suggest that this has serious implications for the profession's ability to ensure patient-centred practice, which is likely to be a key component of any new quality outcome measures in dental care.

In previous work we have $\operatorname{proposed}^{27}$ a model of PCC that incorporates a hierarchy of information and choice built on four foundations of good practice. This paper presents our model as a practical guide to the provision of patient-centred dentistry and a way of bridging the gap between the rhetoric of patient-centred practice, which is widespread, and a shared understanding of how this might be implemented within the dental clinic. Our model is designed as a guide to thinking practically about the steps that need to be undertaken in the clinic, in order to turn good practice into patient-centred 
practice. We start with a brief overview of current understanding of PCC before presenting the model and exploring its implications for dental practice and improved patient outcomes.

\section{DEVELOPING A MODEL OF PATIENT-CENTRED PRACTICE}

Despite the popularity of the concept of PCC, to date, there is not one clear conceptual framework to understand and measure PCC. Although there are several instruments ${ }^{28}$ all measuring perceptions of PCC in medicine, each one emphasising different aspects of PCC, there has not previously been one, widely accepted, definitive model of patient-centredness. Mead and Bower ${ }^{29,30}$ and Stewart et al., ${ }^{31}$ however, have been instrumental in putting forward empirically arrived at models of patient-centredness that may be combined into a framework of what PCC is and how it might be broadly conceptualised.

Mead and Bower see PCC as consisting of five dimensions, namely of a biopsychological perspective, seeing the patient as person, sharing power and responsibility, building a therapeutic alliance and seeing the doctor as person. Stewart et al. on the other hand, see patient-centred care as consisting of six broad dimensions, which they label: exploring both the disease and illness, understanding the whole person, finding common ground, incorporating prevention and health promotion, enhancing the doctor-patient relationship and finally, being realistic.

\section{THE FOUNDATIONAL COMPONENTS}

Examining both of these frameworks of PCC together, we propose ${ }^{27}$ that patient centredness may be conceived as a concept that is built on four foundational components:

\section{Exploring illness/disease and the context in which it occurs}

The first component is about clinicians considering not just the symptoms the patient is presenting with but also the effect of the illness on the person's life and individual circumstances. For instance, a consultation about the need for the extraction of a front tooth would need to explore not just the technical aspects of the procedure but the impact that the extraction would have on the person's overall life, from the need for a repeat appointment, to the impact of taking pain-control medication that may interact with other medications, the psychosocial impact of a missing front tooth and the need to have someone look after the patient's children while he/she is at the dental clinic having the tooth extracted. Considerations need to address potential barriers to the successful completion of the treatment and how these might be overcome.

\section{The patient as a whole person}

The second, perhaps related, component is about looking at the person holistically and thus seeking to understand the person's illness within their own unique biopsychosocial circumstances. A consultation that is truly patient-centred looks at the oral health of the whole person. For example, a dental consultation about poor oral hygiene and the need for preventative care taking place with a professional patient who has the opportunity, capability and motivation to brush their teeth twice a day using fluoride toothpaste, would focus on different issues and run quite differently to a consultation on the same topic taking place with an older person who relies on others for help with his/her oral hygiene routine. Similarly, a consultation aimed at improving a toddler's tooth decay will run differently depending on whether their parent is a single mum, from a low socioeconomic group who herself presents with poor oral health, compared to a child whose parents have good oral health as well as the time, knowledge and resources to support their child's daily brushing.

The first two foundational components are about placing the illness and its physical characteristics in the person's own individual circumstances while considering the illness from the point of view of that particular person. This picks up on principle nine of the NICE guidelines on patientcentred practice in the NHS, focusing on care that is tailored to the needs of patients in its broadest sense. ${ }^{4}$

The final two foundational components of current PCC models focus on the relationship between the dental team and their patient. These two components relate to the type of relationship that is needed if patients are to be enabled to make well-informed choices about their health and healthcare.

\section{The ethos of the healthcare professional-patient relationship}

This component is about showing compassion and empathy and developing a long-term relationship that is going to be conducive to informed, engaged decisionmaking. This covers the first principle of the NICE guidance, incorporating the need to treat patients with dignity, kindness, compassion, courtesy, respect, understanding and honesty. These principles are about good quality patient care rather than patient-centred practice per se, but they are part of the prerequisite foundations of PCC.

\section{The process of doctor-patient relationship: reaching common ground/sharing responsibility}

This final foundational component relates to the process through which dental care professionals and patients reach a 'mutual understanding and mutual agreement'11 in three important areas: problem definition, establishing the goals/priorities of treatment and identifying the roles to be assumed by the two partners. The aim is to achieve a common understanding of the health issue in question and, where there is disagreement or divergence, to reach a consensus. For example, if a patient is asking for treatment that is not the most appropriate clinical option from the perspective of the dentist involved, this would be discussed with the aim of achieving consensus and mutual understanding, and with the knowledge that the patient needs to be supported to make an informed decision.

It is this last process that is particularly interesting and challenging in a clinical context and raises questions about the provision of information and patient choice. What does it mean to be truly patient-centred? Does it mean giving patients enough information so they can make the clinically 'right' decision or the decision that is best for them from a psychosocial perspective, which may, in fact, be different? How can a dental care professional be patient-centred if what the patients think they want and need in order to manage an illness or condition is at odds with the clinically-appropriate, health system-constrained choices that dental care professionals can make available to patients? What happens when the two fail to find 'common ground'? How can the dental team carry on being patient-centred in these circumstances? Is it sensible and patient-centred to give patients the illusion of choice where the only choice is to do what the dental care professional recommends, or face ill-health?

We have argued previously ${ }^{27}$ that the foundational components of PCC outlined above are necessary but not sufficient if PCC is the end goal. The questions that are left unanswered in relation to information, choice and how a balanced position can be reached between the dental team and patient in areas of non-consensus need further consideration. Ultimately, however, it not advocated that PCC is about giving patients what they think they want, over and above what clinicians consider safe clinical practice. Rather, the importance of reaching a genuine consensus within a PCC model of practice becomes obvious in cases where patients want what clinicians judge inappropriate. 


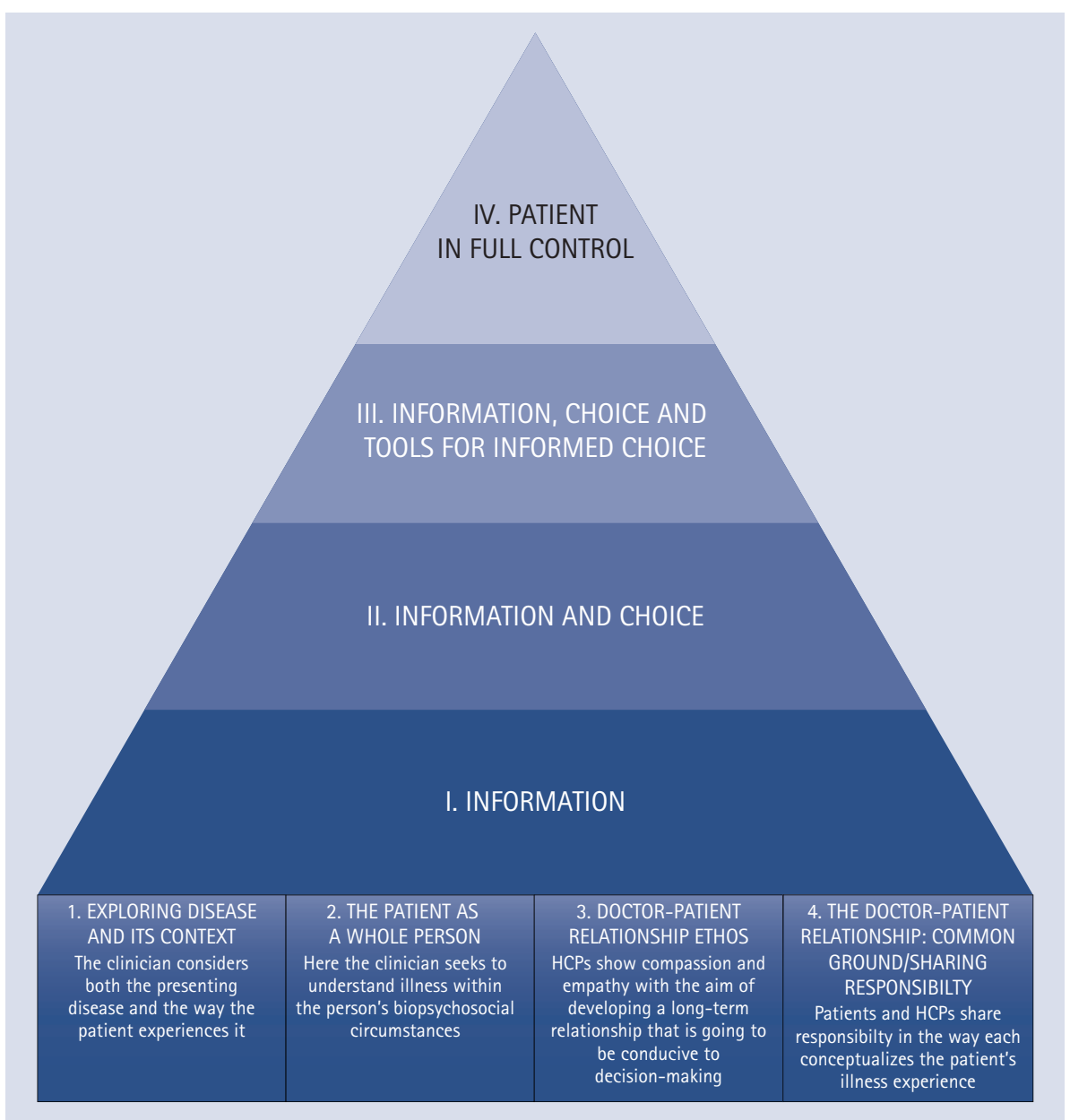

Fig. 1 the hierarchy of patient-centred care

It is our considering the medical literature on PCC as well as complex, practical issues such as these that has formed the basis for this current proposed model of PCC, turning the cornerstones of good practice outlined above into explicitly patient-centred practice. We argue that although the components proposed by current models of PCC are the foundation blocks of a PCC-inspired consultation, clinical practice is also about the amount and type of information that the team makes available to the patient in reaching 'common ground', and the process through which patients are enabled to make an informed, active choice (or not) over how to manage an illness that is key. Furthermore these processes in relation to information and choice can be more or less patientcentred in themselves. That is, a dental care professional may give information about for example, several management options to patients, but not spend any time in discussing how the patient should implement this information in order to manage their oral health. Or, they could advise patients on several different tools for managing oral health, but without giving enough or appropriate information to patients about each one of those tools. Or, it could be that both information and tools to support informed

\section{Level one: information}

Information relevant to the patient's health is provided resulting in a consultation where the dental care professional presents patients with a range of primarily didactic input regarding their condition. This would be what one would expect to see in most routine consultations, regardless of whether they were patient-centred or not. This is ideally evidence-based, information provision at its most basic level. For example, in relation to caries this would be akin to a member of the dental team describing caries and its risks and outcomes and introducing aspects of oral self-care.

\section{Level two: information plus choice}

At level two information is provided to patients as in level one, along with the idea that there is potentially choice between different treatment alternatives. Where treatment alternatives are not an option the idea of choice between treatment and non-treatment is explored. In a consultation focusing on caries levels, the various self-management alternatives would be presented and explored, along with the possibility (and consequences) of consciously choosing to not manage the condition. This differs from level one in that patients are introduced to the idea of having choice over how and whether they manage their condition, while level one assumes that patients will want to follow a dental care professional's advice regardless. So, level two brings into the discussion the idea that patients may choose for example, not to implement or expand their oral hygiene routine or to carry on with a high sugar diet counter to recommendations. Note that it is not proposed that patients should be encouraged to disregard dentist's advice, but rather that the dental team will actively acknowledge that the patient has a choice between looking after their teeth and mouth in the recommended manner or not.

\section{Level three: information, choice plus tools for informed choice}

The focus of level three is the provision of support to enable the patient to make a fully informed choice. That is, all treatment alternatives are considered from a clinical and a psychosocial perspective and patients are supported in arriving at fully informed choices. In an oral cancer clinic, for example, this may involve a discussion about the different treatment options available and the implications of choosing one option over another in relation to the impact of the treatment itself, the evidence base for the efficacy of the treatment and the potential implications of choosing to, or conversely not to, undertake the treatment. Thus, patients are given 
the tools to evaluate the options presented to them and any decisions made are the result of patient-centred, supported choice. Building on level two, rather than the dental team simply acknowledging that the patient has the right not to accept treatment as per clinical recommendations, at level three the consultation expands on the idea of patient choice by helping them explore the various alternatives alongside the pros and cons of each. So in level three PCC, we should see contextualised, tailored, person-centred care.

\section{Level four: patient is in full control of their care}

Here, information, choice and the tools to make an informed choice are given to patients with the ultimate aim of the patients themselves making the final treatment decision that is appropriate to their psychosocial and contextual circumstances. This informed, patientinitiated choice may well be at odds with the most 'appropriate' clinical option. Assuming the process has been followed through that is, the foundational components of PCC have been adhered to particularly in relation to reaching common ground and a truly informed decision-making process has taken place with genuine supported information and choice opportunities, then the dental consultation can be described as meeting the level four aspects of the hierarchy. In these cases, PCC may result in patient decisions which are seemingly at odds with clinical opinion. Conversely, following the same process, PCC may result in a patient inviting their dental care professional to make the treatment decision for them. As long as the patient decision has resulted from an informed, patient-centred process, the patient can be in full control of their care at both ends of the spectrum. So, this fourth level of patient-centred care can be either paternalistic or not, as long as the patient-centred practice process has been followed through the first three stages. We suggest that as long as the patient's 'voice' is the one controlling the process of the consultation, any decision that is made at this stage and as a result of levels one to three having been followed, is a truly patient-centred one. Level four, then, is about helping patients select what they feel is the best care or treatment option for their particular circumstances having engaged in all supporting basic components of PCC, as well as in the preceding levels.

\section{HOW MIGHT THE MODEL OF PATIENT-CENTRED PRACTICE BE OF USE WITHIN DENTISTRY?}

This paper argues that, if care is to be patient-centred, the role of information and choice and the way they are handled within the context and constraints of a consultation need to be clearly determined. The model presented is a theoretically derived hierarchy that builds on existing work drawing out the central process that may turn good practice into patient-centred practice. This model adds detail on how information and choice might be handled and practised in day-today clinical work, to the general processes inherent in PCC, and the broad suggestions about the nature of PCC.

As it stands, this is a tool for reflection about clinical practice rather than about formal documentation; it is anticipated that the dental team will use the hierarchy as a self-assessment tool in their consultations with the aim of noting the level of PCC they are currently practising at and the one they aspire to develop towards, within each consultation. PCC may well appear a fluid, loosely defined concept in the absence of a tool to target specific components of the process and this model makes explicit the thinking that can help clinicians monitor the way they use information and choice in their PCC consultations. It is envisaged that, following any revisions or modifications and empirical testing, a clinical tool to assess the extent to which consultations follow the hierarchy will be developed in the near future. Recent systematic reviews on the subject seem to be supportive of the view that more stringent, clearly defined studies are needed.,22 Here, we have outlined specific, qualitatively different ways of presenting patients with information and choice in practising PCC, and we hope that dental care professionals and other members of the dental team will choose to test it out in day-to-day practice.

1. Institute of Medicine. Crossing the quality chasm: a new health system for the 21st century. Washington, DC: National Academy Press, 2001.

2. Rathert C, Wyrwich M D, Boren S A. Patient-centred care and outcomes: a systematic review of the literature. Med Care Res Rev 2013; 70: 351-379.

3. Inzucchi SE, Bergenstal R M, Buse J B et al. Management of hyperglycaemia in type 2 diabetes: a patient-centered approach. Position statement of the American Diabetes Association (ADA) and the European Association for the Study of Diabetes (EASD). Diabetologia 2012; 55: 1577-1596.

4. National Institute of Health and Care Excellence. Patient experience in adult NHS services: improving the experience of care for people using adult NHS services: clinical guidelines (CG138). London: NICE, 2012.

5. General Dental Council. Standards for the dental team. London: GDC, 2013.

6. Logan H. The patient and the shifting health-care paradigm. J Am Coll Dent 1997; 64: 16-18.

7. Darby M L, Walsh M M. Application of the human needs conceptual model to dental hygiene practice. J Dent Hyg 2000; 74: 230-237.

8. Kulich K R, Berggren, U, Hallberg L R. A qualitative analysis of patient-centreed dentistry in consultations with dental phobic patients. J Health Commun
2003 8: 171-187.

9. Richards PS, Inglehart M R. An interdisciplinary approach to case-based teaching: does it create patient-centreed and culturally sensitive providers? J Dent Educ 2006; 70: 284-291.

10. López-Jornet P, Camacho-Alonso F. Quality of life in patients with oral lichen planus. J Eval Clin Pract 2010, 16: 111-113.

11. Bedos, C, Loignon C. Patient-centred approaches: new models for new challenges. J Can Dent Assoc 2011; 77: b88.

12. Fontana M, Wolff M. Translating the caries management paradigm into practice: challenges and opportunities. J Calif Dent Assoc 2011; 39: 702-708.

13. Miles $L \mathrm{~L}$. The patient-centered practice. Northwest Dent 2011; 80: 83-83.

14. Freeman R. Communicating with children and parents: recommendations for a childparentcentred approach for paediatric dentistry. Eur Arch Paediatr Dent 2008; 9: 16-22.

15. Merchant V A. Evidence-based dentistry: answering patient-centered questions. J Mich Dent Assoc 2011; 93: 16.

16. Ford R T, Larson T D, Schultz C J. Teaching comprehensive treatment planning within a patient-centered care model. J Dent Educ 1988; 52: 114-117.

17. Phillips C. Patient-centered outcomes in surgical and orthodontic treatment. Semin Orthod 1999; 5: 223-230.

18. Fier M A. Patient-centered treatment planning: part 1. Dent Today 2007; 26: 56-61.

19. Eriksen H M, Bergdahl J, Bergdahl M. A patientcentred approach to teaching and learning in denta student clinical practice. Eur Dent Educ 2008; 12: 170-175.

20. Goldberg $\mathrm{K} L$. the role of the dental team in implementing EBD and communicating the evidence with your patients. J Evid Based Dent Pract 2008; 8: 159-161.

21. Janssen D. Because I have a choice, I will choose to do the right thing. J Am Coll Dent 2009; 76: 24-26.

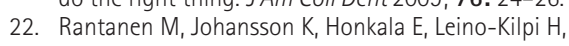
Saarinen $\mathrm{M}$, Salanterä S. Dental patient education: survey from the perspective of dental hygienists. Int J Dent Hyg 2010; 8: 121-127.

23. Leles C R, Martins R R, Silva E T, Nunes M F. Discriminant analysis of patients' reasons for choosing or refusing treatments for partial edentulism. J Oral Rehabil 2009; 36: 909-915.

24. Cohen $L A$, Bonito $A J$, Eicheldinger $C$ et al. Comparison of patient centeredness of visits to emergency departments, physicians, and dentists for dental problems and injuries. J Am Coll Dent 2010; 77: 49-58.

25. Madhan B, Rajpurohit A S, Gayathri H. Attitudes of postgraduate orthodontic students in India towards patient-centered care. J Dent Educ 2011; 75: $107-114$.

26. Mills I, Frost J, Moles D R, Kay E. Patient-centred care in general dental practice: sound sense or soundbite? Br Dent J 2013; 215: 81-85.

27. Asimakopoulou K, Scambler S. The role of information and choice in patient-centred care in diabetes: a hierarchy of patient-centredness. European Diabetes Nursing 2013; 10: 58-62.

28. Hudon C, Fortin M, Haggerty J L, Lambert M, Poitras M E. Measuring patients' perceptions of patientcentred care: a systematic review of tools for family medicine. Ann Fam Med 2011; 9: 155-164.

29. Mead N, Bower P. Patient-centredness: a conceptual framework and review of the empirical literature. Soc Sci Med 2000; 51: 1087-1110.

30. Mead N, Bower P. Patient-centred consultations and outcomes in primary care: a review of the literature. Patient Educ Couns 2002; 48: 51-61.

31. Stewart M, Belle Brown J, Weston W W, McWhinney I R, McWilliam C L, Freeman T R. Patient-centred medicine: transforming the cinical method. Oxford: Radcliffe Medical Press, 2003.

32. Olsson LE, Jakobsson Ung E, Swedberg K, Ekman I. Efficacy of person-centred care as an intervention in controlled trials a systematic review. J Clin Nurs 2013; 22: 456-465. 